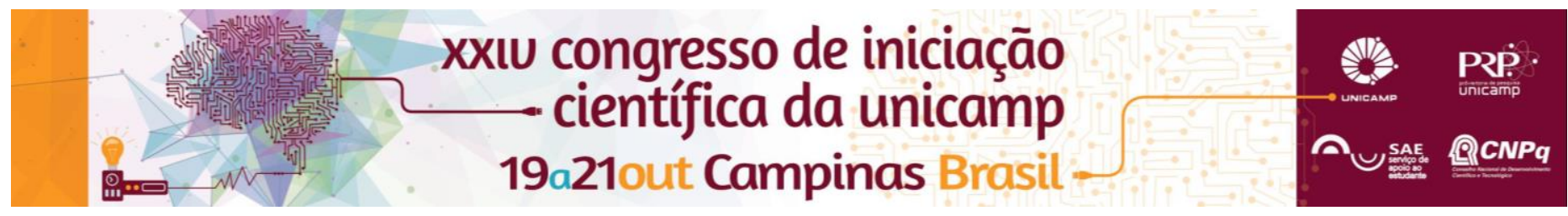

\title{
Utilização de Ferramentas Digitais no Marketing Atual e Mudanças na Comunicação de Marcas com o Consumidor Final
}

\author{
Adriana Bragatin*, Maria Carolina de A. F. de Souza.
}

\begin{abstract}
Resumo
A difusão de tecnologias digitais, particularmente as de comunicação, provocaram mudanças no marketing como disciplina e como função e possibilita (mas não garante) a criação de um relacionamento entre marca e consumidor mais estreito do que aquele permitido pelos meios de comunicação tradicionais. Esta pesquisa busca compreender quais e como as ferramentas digitais estão sendo utilizadas no mix de comunicação de marcas consideradas valiosas e, se a utilização dessas ferramentas contribui para a formação de um relacionamento mais estreito, compatível com um novo tipo de consumidor mais bem informado e com acesso a um grande número de meios de comunicação.
\end{abstract}

Palavras-chave: Comunicação de Marcas, Ferramentas Digitiais de Comunicação, Marketing.

\section{Introdução}

A tradicional visão do marketing fundamentada nos 4 Ps: produto; preço; promoção (incluindo promoção de vendas, propaganda e publicidade) e distribuição (place, em inglês), deixou de ser suficiente e foi sendo complementada com $O$ avanço da tecnologia de informação e comunicação (KOTLER; KARTAJAYA; SETIAWAN, 2010). As mídias sociais proporcionam interação de consumidores com outros consumidores e com as empresas simultaneamente, fazendo com que as estratégias de marketing, particularmente as de comunicação, fossem revisadas e adaptadas a esse novo cenário. Porém, na prática, quais foram as mudanças no relacionamento entre empresa e consumidor no que se refere à comunicação de marcas? Será que as marcas utilizam as modernas ferramentas digitais de comunicação a fim de promover um relacionamento mais interativo com o consumidor, que, em meios tradicionais de comunicação, tem pouco, ou nenhum espaço para participação mais ativa? São essas as principais questões que conduziram este estudo.

\section{Resultados e Discussão}

Foi analisada a presença das cem marcas mais valiosas, segundo o ranking da Interbrand (2015), nas redes sociais Twitter, Facebook, Youtube, Instagram e Google Plus, e foi possível observar que todas fazem uso de pelo menos uma dessas redes sociais e que $46 \%$ possuem perfis em inglês em todas as redes sociais citadas e perfis em português em três ou mais redes sociais, evidenciando, portanto, a forte presença das marcas nos meios digitais de comunicação. Youtube, Twitter e Facebook foram as redes sociais mais utilizadas pelas marcas analisadas.

Google, McDonald's, MTV, KFC, Discovery, Nike, Pepsi, Starbucks, Microsoft, Samsung, Visa, BMW e Chevrolet são as marcas que possuem os maiores números de seguidores nas três redes sociais citadas e, por isso, seus perfis oficiais foram analisadas nos meses de maio e junho de 2016, tendo em vista o tipo de conteúdo, linguagem e formato das publicações; comentários realizados pelos usuários e respostas e interações publicados pelos perfis oficiais. Foi possível perceber que grande parte do conteúdo publicado nas redes sociais é de natureza promocional e consiste na divulgação de novos produtos e recursos inseridos em situações de consumo através de imagens, vídeos e textos em que a marca é diretamente citada. Nessas postagens há uma intensa interação por parte dos usuários que comentam e publicam elogios, dúvidas e reclamações sobre produtos e marcas, porém apenas algumas marcas respondem a essas interaçoes. As marcas pertencentes ao setor da mídia não interagem com os usuários e as marcas pertencentes ao setor de bens de consumo não duráveis respondem a uma maior quantidade de comentários, dúvidas e reclamações no Facebook e Twitter, sendo esta a rede social em que as marcas mais interagem com seus consumidores. Foi possível perceber também que as reclamações não são solucionadas através desses canais de comunicação. É comum conter, nas respostas enviadas pelo perfil oficial da marca, endereço de e-mail e telefone de atendimento ao consumidor com pedido do usuário formalizar sua reclamação nesses meios de comunicação mais tradicionais entre empresa e consumidor final. Os perfis das marcas analisadas no Youtube não apresentaram nenhum tipo de interação com os comentários, dúvidas e reclamações publicados pelos usuários, mostrando-se uma rede social utilizada somente para a publicação e divulgação de vídeos.

\section{Conclusões}

As redes sociais permitem uma comunicação bidirecional entre empresas e consumidores, porém na prática, as marcas utilizam essas novas ferramentas de comunicação para promoverem e divulgarem seus produtos, promoções e eventos, colocando em segundo plano a interação com seus consumidores. Uma pequena quantidade de comentários, dúvidas e reclamações são respondidas pelos perfis oficiais das marcas e as reclamações não são solucionadas através das redes sociais, sendo utilizado para isso os canais tradicionais de atendimento ao consumidor como telefone e e-mail.

\section{Agradecimentos}

Ao $\mathrm{PIBIC} / \mathrm{CNPq}$ e à minha orientadora Dra. Maria Carolina de A. F. de Souza, por todos os ensinamentos sobre marketing e pesquisa.

INTERBRAND. Best Global Brands 2015 Ranking. Disponível em: <http://goo.gl/IA6UEI >. Acesso em: 02 ago. 2016.

KOTLER, P.; KARTAJAYA, H.; SETIAWAN, I. Marketing 3.0: as forças que estão definindo o novo marketing centrado no ser humano. Rio de Janeiro: Elsevier, 2010. 